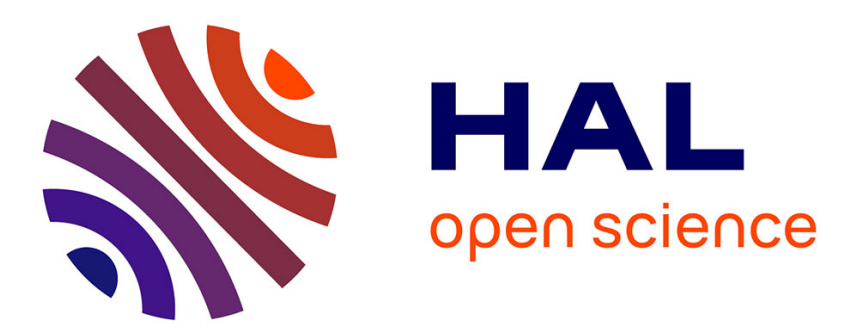

\title{
Information exchanges between experts for thermoset composites design for recycling
}

Nicolas Perry, Stéphane Pompidou, Olivier Mantaux

\section{To cite this version:}

Nicolas Perry, Stéphane Pompidou, Olivier Mantaux. Information exchanges between experts for thermoset composites design for recycling. International Journal of Environment and Waste Management, 2014, pp.15. hal-00948121

\section{HAL Id: hal-00948121 \\ https://hal.science/hal-00948121}

Submitted on 17 Feb 2014

HAL is a multi-disciplinary open access archive for the deposit and dissemination of scientific research documents, whether they are published or not. The documents may come from teaching and research institutions in France or abroad, or from public or private research centers.
L'archive ouverte pluridisciplinaire HAL, est destinée au dépôt et à la diffusion de documents scientifiques de niveau recherche, publiés ou non, émanant des établissements d'enseignement et de recherche français ou étrangers, des laboratoires publics ou privés. 


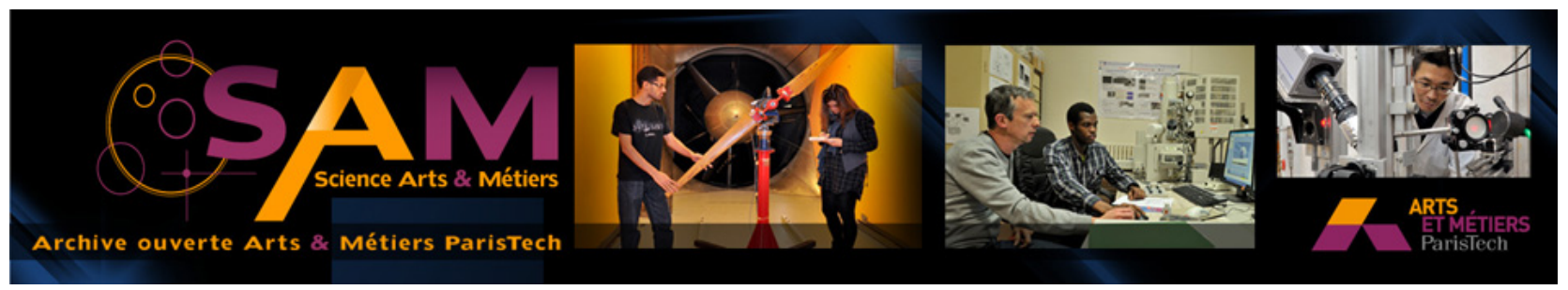

Science Arts \& Métiers (SAM)

is an open access repository that collects the work of Arts et Métiers ParisTech researchers and makes it freely available over the web where possible.

This is an author-deposited version published in: http://sam.ensam.eu

Handle ID: .http://hdl.handle.net/10985/7760

\section{To cite this version :}

Nicolas PERRY, Stephane POMPIDOU, Olivier MANTAUX - Information exchanges between experts for thermoset composites design for recycling - International Journal of Environment and Waste Management p.15 - 2014 


\title{
Information exchanges between experts for thermoset composites design for recycling
}

\author{
Nicolas Perry \\ I2M - UMR 5295 - Arts et Métiers ParisTech, F-33400 Talence, France. \\ E mail : n.perry@i2m.u-bordeaux1.fr
}

\section{Stéphane Pompidou, Olivier Mantaux}

\author{
I2M - UMR 5295 - IUT Bordeaux 1, F-33175 Gradignan, France. \\ E mail : s.pompidou@i2m.u-bordeaux1.fr \\ E mail : o.mantaux@i2m.u-bordeaux1.fr
}

\begin{abstract}
The use of composites in industry is ever increasing. However, endof-life solutions for composites are still under development. In this paper, a solution linking design strategies with a recycling process for thermoset composite materials is proposed. The recovery solution for these materials is a supercritical water solvolysis process. The needs and multi-disciplinary skills required for taking recycling possibilities into account in the early stages of product design and the necessity to standardize product-recycling capabilities based on design requirements will be discussed. The paper highlights the need for designers to take a functional approach into consideration, including characterization of materials behavior, recycling process limits, constraints and opportunities. This paper will show the first lessons learned from experiments, using this technique.
\end{abstract}

Keywords: Design for recycling, eco-design, organic matrix composites, composite recycling, knowledge exchange

Reference to this paper should be made as follows: Perry, N., Pompidou, S. and Mantaux, O. (xxxx) 'Information exchanges between experts for thermoset composites design for recycling', Int. J. Environment and Waste Management, Vol. X, No. Y, pp.000-000.

Bibliographical notes:

N.Perry received his PhD in Mechanical Engineering at Nantes University, focusing on the material and process interaction for high energy welding processes of titanium and stainless steels. As an Associate Professor he searches, from 2001 to 2007 at the Research Institute on Communications and Cybernetics of Nantes, on the integrated design approached for industrial engineering application. Since 2007 at Bordeaux University the research topics switched to composite domain and eco-design. He is now Professor at Arts et Metiers ParisTech Bordeaux, working on the integration of end of life into the design method, and recycled materials development.

S. Pompidou achieved a PhD in Mechanical Engineering in the University of Bordeaux in 2003; a model of crack deflection along an interface, or within the interphase of ceramic matrix composites, was proposed. As a postdoctoral research scientist, he worked on micromechanics-based evaluations of 
composites' interfaces properties, for the European project Vaftem. As an Assistant Professor of the Mechanical Institute of Bordeaux, he first worked on the characterization of self-healing thermoset matrices. He recently joined the ecodesign research group, and works on the formalization of downcycling concepts in second generation carbon fiber-based composite materials.

O.Mantaux is associate Professor at University of Bordeaux (France). He obtained his Ph.D in "Mechanical Engineering" at the University of Bordeaux 1. $\mathrm{He}$ is now head of the recycling research group of I2M Laboratory in Bordeaux. $\mathrm{He}$ is carrying out research activities with interests in recycling of polymer and composites materials. He works on national recycling research projects: VALEEE for the recycling of polymers from WEEE and RECCO for the recycling of carbon-composite materials. The main objective of these researches is to develop new processes in order to perform recycled materials as a function of their future applications.

\section{Introduction}

Today, the key focus for the transport industry is to make lighter vehicles. Reduction in weight leads to a decrease in energy consumption and $\mathrm{CO}_{2}$ emissions. Reducing greenhouse gases and pollution is one of our society's main challenges as it strives for sustainable development. Composites provide good opportunities for combining high modulus materials with free definitions of geometry. As a result, their use in industry is increasing. The aerospace and aeronautics sectors have integrated composites at different levels for their products (organic matrix based for cold applications and metallic or ceramic-based composites for high temperature applications).

This study is based on European regulations and tend to anticipate their future evolutions (such as REACh or electronic wastes) (REACh, 2006)(WEEE, 2002). Today, in the automotive industry, the limits of the use for the composites are their potential recyclability. Indeed, in a global and eco-friendly approach, one must analyze and take end-of-life solutions for systems into account, at an early stage of their development process. Moreover, in the case of automotive, regulations impose a 95\% ratio of recycling of an out-of-use vehicle.

The term de-manufacture has become more and more common, especially in the electronics industry. It characterizes the process of recycling materials and products, including end-of-life strategies and logistics in product development (Berry, 1996) (Gaustad et al., 2010). Design engineers have to balance safety, energy efficiency and cost. Unfortunately, they rarely get to the point of thinking about what will happen to the product at the end of its useful life (Kriwet et al., 1995) (Vallet et al. 2010).

However, as new materials and technologies are developed, the challenge that recyclers face in safely and economically recycling those products grows ever more difficult (Calcott et al. 2005). Recycling a product means: (i) have a recycling technology available, (ii) get a dismantle solution and an access for the product, and (iii) dispose identification plus selection (maybe clean or pure) possibilities for the materials. Moreover, the recycling processes have to balance the technical, economical and environmental aspects of the end-of-life proposal. Composite applications have opened up a new field of research and development in the domain of new recycling processes. 
Water under supercritical conditions gives the opportunity to recover composite reinforcements (carbon fibers) and open new opportunities for second-life composites.

We are focusing on research activities that aim at integrating recycling constraints in the design stage of composite parts. It is necessary to promote discussion between designers and recyclers in order to innovate in the definition of new recycled composite products. This means that information from both actors will be shared. However, it also implies that information from the material level should be enriched (for both designers and recyclers point of views). Therefore, it is necessary to include third parties in the discussion: experts in material and mechanical characterization. This expertise makes the link at the material level giving the expected information for designers and recyclers, enabling the material specification.

The second section of this paper presents an overview of composite recycling possibilities and the technical and economic reasons for its development. The third part will focus on the design for recovery issue and the specificities related to composite design. The fourth section will explain our understanding in terms of skills, needs and know-how required for addressing this issue. Before concluding, the last section will illustrate some feedback and the first lessons learned regarding eco-design for composites.

\section{Composites recycling motivations and solutions}

Future regulatory constraints are driving industries to develop efficient end-of-life alternatives based on technical and economic constraints. For carbon and aramid based products, high prices (e.g. carbon prepreg: approx. $180 € \bullet \mathrm{kg}-1$; Kevlar@: approx. 150 $€ \bullet \mathrm{kg}-1)$ and the world shortage in raw materials production, are the leitmotiv for finding technical and cost-effective recycling solutions. In such cases, second use of composite fibers will be dedicated to the manufacture of medium or low loaded parts (non-structural in many cases). Indeed, the recycled fibers and reprocessed semi-products have to reach the full acceptance and the trust of users (designers), regarding their health and quality. In fact, many stakeholders upon seeing the "recycled" label still tend to think of low quality (Piñero et al., 2008) (Pimenta et al., 2011). However, as far as recycled carbon fibers are concerned, this is far from the truth. Methods exist today by which carbon fibers and prepreg can be recycled, and the resulting recyclate retains up to 90 percent of the fiber's mechanical properties. In some cases, the method enhances the electrical properties of the carbon recyclate because the latter can deliver a performance close or superior to the initial material (Perry et al., 2010a). So it is necessary to create demand for recycled fiber, by packaging it in a form useful or attractive to end-users. For example, cheap materials with very good properties could find larger applications than composites today. Moreover, this material, resulting from a reprocessing path, is more environmental friendly, and has the potential of a new recycling loop. In this way this is a down-cycling solution as explained by McDonough and Braungart (2002). We develop a remanufacturing solution in order to limit or master the properties losses.

To make such a recycled product cycle viable, the key factors are mainly the waste deposit quantity and its availability. In order to ensure the efficiency of the recycle path collecting and identifying infrastructure must be established in order to guaranty and improve the weighting of the recycled flux. Finally, the end-user must have confidence in the quality of the product in terms of robustness and value. Mechanical, physical and 
chemical studies must be purchased in order to enrich the recycled material data and confirm the properties of recycle fibers, semi-products and structures. These actions have been done successfully in the plastics industry. For example, forms of identification labels were added on plastic parts to facilitate collecting and sorting. Most composites manufacturers are already engaged in waste management procedures, pushed by the REACH regulation; as a result, they recycle waste materials on the workshop when collecting and processing solutions are proposed.

Thermoset matrix based composites designers and manufacturers are currently taking two different directions. On one hand, they are trying to increase the use of green composites or bio-composites, on the other hand, they develop or improve recycling technologies. In the first place, the interest of using bio-composites lies in their small environmental impact Indeed they are made of:

1) a bio-polymer matrix reinforced by synthetic fibers (glass, carbon, Kevlar@);

2) a petroleum-derived matrix reinforced by natural fibers (kenaf, flax, hemp, bamboo, coconut stems);

3) biopolymers (e.g. polylactic acid - PLA- or polyhydroxyalkanoates - PHA) reinforced with natural fibers.

Natural fibers are being tested to estimate their reinforcement properties. They promise to be the future solution for organic matrix composites parts (Feng, 2010) (Mohamad, 2010). For example, their mechanical properties can compete easily with glass fibers. Indeed, their specific density ranges from 20 to 45 and their tensile stress ranges from 400 to $1500 \mathrm{MPa}$. Furthermore, solutions already exist for high-performance mechanical composites, for example by improving the weaving processes (Weager, 2010). Biopolymers or bio-compound (a combination of bio-polymer and petroleum derived polymer) have also been studied (Bourmaud and Baley, 2009). For example, they come from PLA derived from cornstarch, or PA11 from castor seeds and its ricin protein. On the one hand, their carbon footprint is reduced, by the use of a bio renewable material, and on the other hand by the increase of the recyclability potential.

In addition, the end-of-life impact awareness helps developing recycling technology. The thermoset matrix can be removed either by burning or grinding techniques. It's cheap but very aggressive for the carbon fibers (Mantaux et al., 2004 and 2009). Complex thermal, chemical and mechanical processes are needed to obtain high quality recycled carbon fibers. Pyrolysis or solvolysis are two of these very promising solutions. However, there are some limitations; for example, it is impossible to recycle different categories of matrix simultaneously. At the same time, specific coatings (e.g. metallic cladding for electric behavior) are not compatible with some processes. Thus, specific requirements must come from the recycling stages if they are to be efficient. The most obvious but also important thing is to extract and free all the metallic inserts, even before grinding. Moreover, before recycling, the products have to be dismantled and adapted to the recycling process reactor. These reactors are mainly cylindrical Cutting operations are compulsory.

In southwest France, composites recycling will increase in terms of quantity due to the creation of two dismantling platforms:

1) TARMAC platforms are dedicated to civil aircraft applications in collaboration with Airbus, EADS Sogerma. TARMAC first focuses on the re-use and the certification of replacement parts in aircraft maintenance,

2) P2P platform (close to Bordeaux) deals with the disassembly of ballistic weapons. 
A consortium of rocket manufacturers (EADS Astrium Space Transportation, Snecma Propulsion Solide, etc.) are working together on the RECCO project (RECCO is a french acronym for composites recycling). The final goal is to validate an industrial solution and an industrial demonstrator for composite recycling. The solvolysis process is chosen for removing the thermoset matrix (Aymonier et al., 2006) (Cunliffe et al., 2003). In this technological and industrial background, we promote an early integration of the recycling constraints and possibilities in the design process of carbon composite parts. The next sessions will explain the integration levels we face in order to develop a design for recovery approach.

\section{Composite design for recycling / recovery}

In order to take the end-of-life information into consideration in the product design phase, we naturally opted for design for x approaches (Wallace et al., 1993) (Hauschild et al., 2004). In our case, we worked on design for recovery (instead of recycling) taking common consideration (disassembly in this case) that should lead designers to propose solutions for products. In this perspective, all the recycling requirements are considered as input (data) that must be taken into account in a product's functional specifications. In addition, from a semantic point of view, we promote the use of the term recovery instead of recycling, in order to emphasize the second life and second use of the product or material after the recycling phase. Besides, we shift from the cradle to grave cycle to the spirit of the cradle to cradle (McDonough et al., 2002 \& 2003) (Braungart et al., 2007). Thus, even if we are using design for recycling methodology, or using the term recycling, we take it as a dynamic state, as a rebirth for future use and not as a static and final goal. That means considering future product design or future second life material at the recycling level. It also means that the material down-cycling effect have to be taken into account in order to improve material data base with its different evolutions and recycling solutions. In other words, we are in two dual areas of research. Firstly, design for the end of life can be summarized as design for recovery. Secondly, from recycling to design, the research deals with robust material recycled for design.

Design for recovery challenges aim to protect the environment and create sustainable means for preserving our resources and reducing energy loss and pollution. It seeks to achieve two very basic goals. The first one is to eliminate or reduce the use of hazardous or toxic materials which may present a serious threat to the environment, or put a recycler's workforce in jeopardy. The second is to discourage the use of materials that are not recyclable or manufacturing techniques that make a product non-recyclable using current technologies. The best time to address these issues is during the design stage (Ferro and Amaral, 2006). Addressing a product's end of life is essential at the very beginning. Adopting this premise helps to ensure an efficient recycling chain, this goes well beyond the scrap processor to the mill, smelter, or extruder that will take the recycled materials and make them into new materials. Design for recycling is a mindset that all design engineers must embrace if they hope to have their products considered as environmentally friendly. As mentioned before, design for recycling is driven by governmental mandates like the European Union's waste electrical and electronic equipment directive (WEEE) or end-of-life vehicle (ELV) directive (in Europe, the rate of re-use and recovery should reach $95 \%$ in 2015 , and $85 \%$ for re-use and recycling, in average weight per vehicle and per year). 
There is more than environmental compliance at stake here. As new materials are developed, such as carbon-based composites, they bring about a new threat in terms of recycling. As these new materials are introduced into products and are replacing materials that have been recyclable for generations, they affect recyclability negatively both practically and financially, and can have a devastating impact. Even materials that are recyclable can pose a problem when used in combination. Take for instance a product that is made from many different types of plastics. Today's recycling technology can only sort two or three different types of polymer materials using a mechanical solution, at best. Composites effectively become non-recyclable, or at least the plastics fraction of that product will be non-recyclable (Seager et al., 2004) (Perry et al., 2010b).

Therefore, in order to address the global problem, we are working on different levels: (i) design teams, (ii) design methods and (iii) design tools, so as to reduce the gap between the existing recycling solutions or bio-composites possibilities, and designer's today solutions. Not only engineers have new materials and new product design solutions for eco-responsible products, but there are now also different tools available to help model and evaluate the solutions and the impact of the product life. This end-of-life requirements definition, also points out the needs, in terms of maintenance or parts fixing.

Unfortunately, the results of these rating tools depend on the information available. Most of the time, little information is available about the life and end of life of a product in the design stage. Furthermore, in the case of recycling processes under development, it is necessary to anticipate the potentiality of the technologies and their applications. The uncertainty of decisions will therefore be increased. Indeed, design decisions, in terms of end-of-life consequences, will undoubtedly appear 5 to 20 years later.

Before giving further explanation, it is important to remember that composite design is complex due to the fact that it is necessary to simultaneously define (i) geometry and shape, (ii) materials (fiber and matrix) and the reinforcement orientations, and (iii) manufacturing process. These three topics are linked and inter-dependent in the design and optimization process. For example, laminates selections limit shapes possibilities and depend on manufacturing capability. Consequently, as illustrated in figure 1 , the ecodesigner has to juggle with constraints from various sources, in addition to internal constraints and relation-ships of the composite design. Up to now, these additional constraints are not taken into consideration, except for the consequences of the European regulation (REACh) which focuses on manufacturing aspects. 
Figure 1 Composite design constraints.

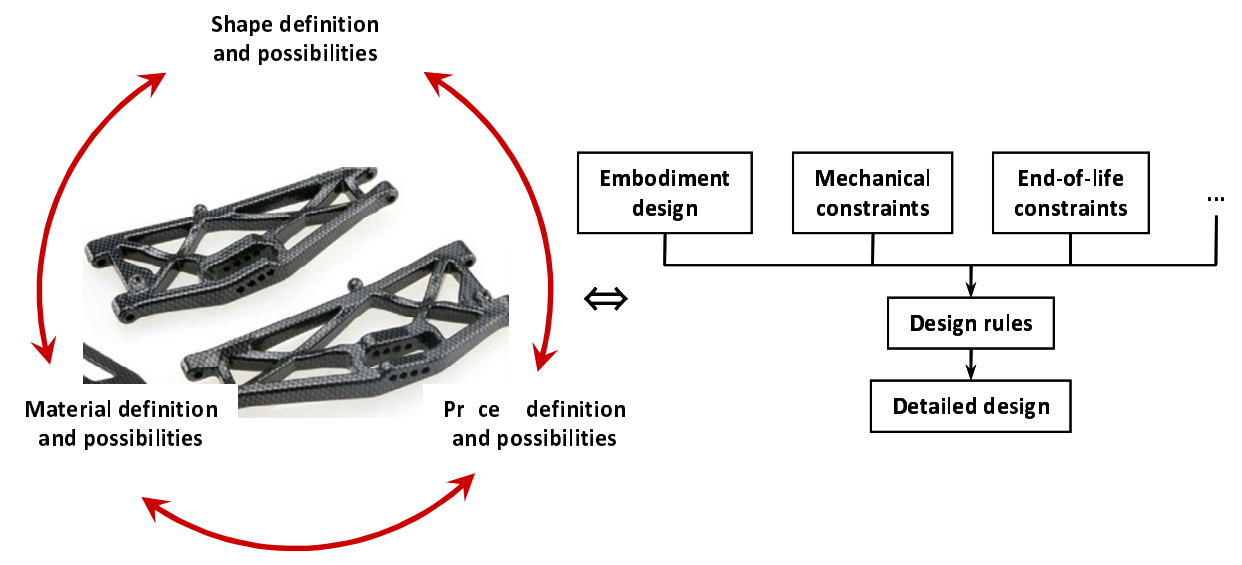

\section{Levels of complexity for the integrated design}

Integrated design means addressing the recycling process development issue carefully while at the same time, proposing the possibility of including such evolutions in design methodology. We identified three main problems:

- the first is linked with recycling physics and scheduling to link and reach design methodologies;

- the second is dedicated to the uncertain and non-complete nature of the available information;

- the third problem has to do with competencies and skills needed to for the design of robust recovery problems.

We subscribe to the proposal of Nonaka who explains that information becomes knowledge when it is used by a human in a cognitive process. It becomes know-how and even skill when this knowledge is efficiently used and applied with others (Nonaka et al., 2000).

\subsection{Physics and timetable}

This part deals with the knowledge of integration in design of the recycling process. These processes are most of the time under development, searching for breakthroughs, innovations and applications. The recycling rules that must be included in the design process are still under formalization while designers must take decisions. Furthermore, the decisions taken today affect the product much later. Figure 2 shows the core elements that build the skeleton of a product's end of life. Different stakeholders are included in the loop and should point out information, expected data and decision rules they apply to switch from one stage to another. The different schedule between real recycling process and part design increases the integration difficulties. For existing and robust end-of-life paths, constraints and material re-process and re-use are well known. For new recycling processes, robust validation can take time while designers have to take decisions now. An extreme example is nuclear plants. Built 40 years ago, there are still no efficient end-oflife solutions as their dismantling will soon begin. Research and development teams are 
banking on some kind of technological breakthrough to guide developments in recycling. Innovation is needed not only in the recycling phase, but also for all the key stages. It is important to improve disassembly techniques (see design for assembly-disassembly approaches) or selection efficiency (Boothroyd and Alting, 1992) (Aymonier et al., 2006) (Lopinet et al., 2010). At the end of the process, it is essential to develop innovative and valuable uses to compete with virgin raw materials (for similar characteristics) or to find new opportunities, at the very early design of the recycling path.

As far as composites are concerned, new processes enable fibers to be recovered with very little distortion and fracture from the initial disposal of the composite part. Supercritical fluids (id. es. solvolysis) give such opportunities (Loppinet-Serani et al., 2010) (Kromm et al., 2003). However, the problem of alignment and restructuration of the fibers still remains. Competences (knowledge and know-how) and skills on fibers spinning and weaving have been integrated by recycling teams. Other alternatives consist in reprocessing medium size flat rectangular pieces of $1 \mathrm{D}$ or $2 \mathrm{D}$ carbon fibers. The innovation consists in proposing a patchwork's part design approach. Moreover, specific works must identify the mechanical characteristics and efficient strategy for material characterization according to the product design development phase, from the recycled fibers to the final structure (Laurin, 2005) (Rollet, 2007). This pyramidal testing problematic, from the micro to macro behavior, at all the stages of the product (from the fiber to the structure), must integrate the uncertainty of complex but in real case tests (Dennison, 2010) (Ladevèze, 2006).

\subsection{Information access and result trusts}

Figure 2 is a starting point for identifying the existing information available at each stage of the process. This map integrates the different stakeholders, and identify which kind of information is needed or available, who is the owner or requires this information (Bernard et al., 2007). This map is the base of the information system (PLM based) in order to link information and engineering tools for the product development phase and the material recycling and characterization. Rosemann proposed an engineering platform in order to optimize disassembly and recycling strategy at the early stage of the product design. It is based on 3 tools: i) ReGrEd: a graph interface-modeling tool of products, ii) RecyKon: a recycling-engineering-kit to help the functionality analysis, and iii) DisPlay: a disassembly Planning System. This platform was the premise of the today PLM system that can be adapted to early end of life integration (Rosemann et al., 1999).

In the perspective of a classical $\mathrm{V}$ cycle of product development, two elements arise. Firstly, the kinds of data and their accuracy depend on the end-of-life solution chosen. Indeed, as illustrated in Figure 3, in the case of a re-use of product, the product life information might need to be certified and guaranteed for compliance. The materials database will store all this information, structured for each recycling stage. The designer will use the data stored. Nevertheless, in many cases, the kind of data required is known, but the real value of the data is either unknown, or fuzzy, or ranges out of the limits. As a result, design evaluation becomes uncertain. Therefore, end-of-life solutions are not fully defined at an early design stage. Nevertheless, these initial decisions will impact the environmental footprint. In addition, as illustrated in part 4.1, an efficient end-of-life solution might not have been developed yet. Consequently, end-of-life evaluations must be used with care, dividing the trustable results with the uncertain ones. Similar levels of 
information completeness can compare different solutions. Otherwise, the results should be taken as trends or qualitative comparisons.

Figure 2 Recycling process analyses in the perspective of the design product specification and recycling process information

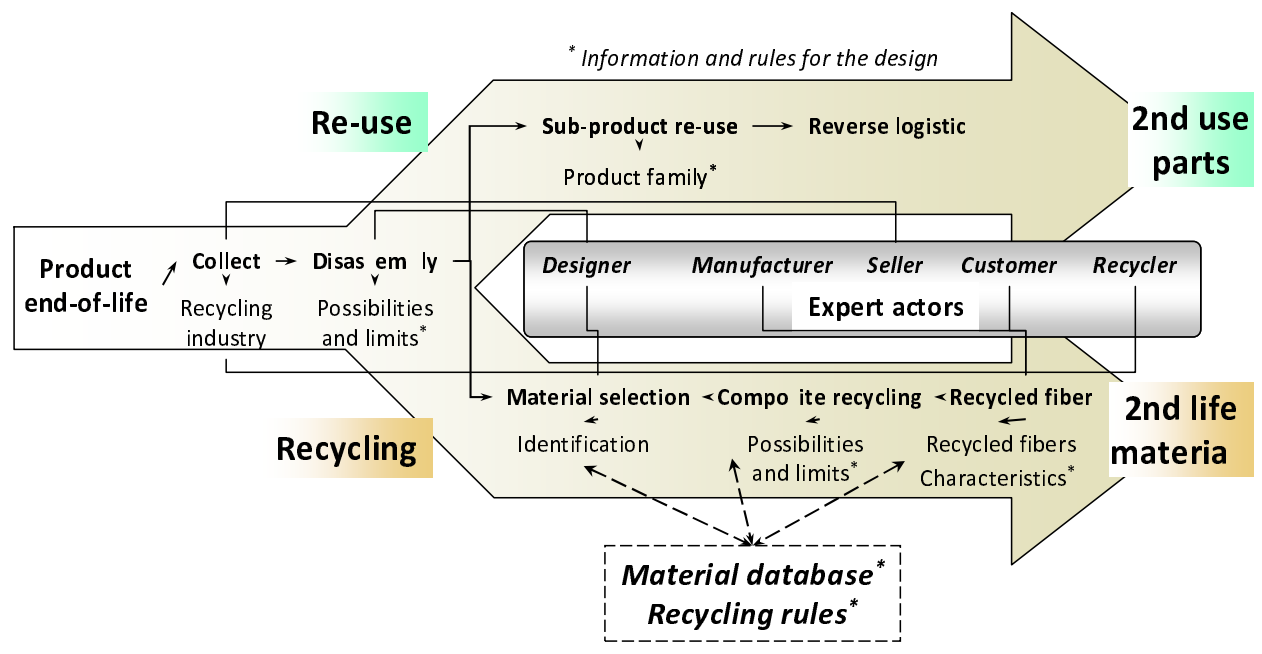

Figure 3 V cycle for information exchange

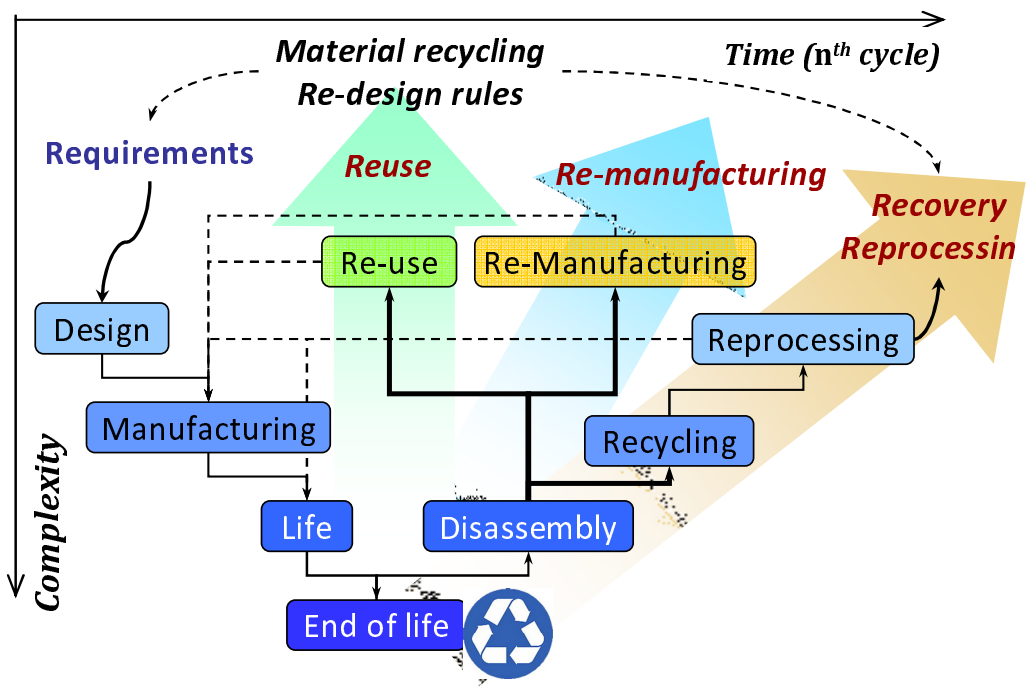

It is necessary to formalize and map the design process cycle, with each key decision, regarding the life and end-of-life impact. The decisions will need data, decision rules, etc. In addition, as started in figure 2, all the information must be captured in detail (requirements and constraints) in order to generate recycling rules. The connection link between the two aspects, identified with the use or the generation of the same data, will link designer to recycler. 


\subsection{Multidisciplinary needs}

The previous section explains how we will create the link between recyclers and designers. However, in many cases, designers need data regarding a specific characteristic (e.g. maximum tensile stress) and the recyclers are not able to give such information. Inversely, the recyclers have to know about life damage, but the designer can only inform on the use cases employed for the design. Consequently, complementary information arises in this dual relationship. Material and product characterization is compulsory at different levels. People coming from material, chemical and mechanical fields will be able to provide a way of translating the requests or the requirements into real data. Indeed, many different characterizations must be carried out before and after the recycling process.

Figure 4 Summary of the interrelation of the three skills

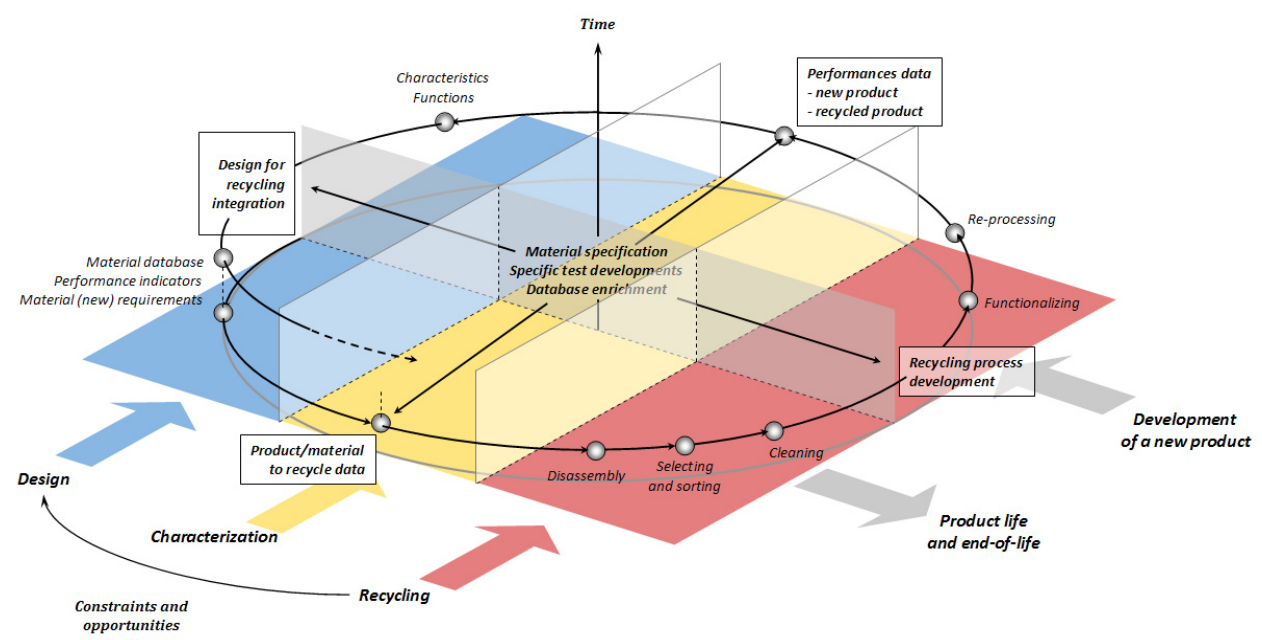

For example, assembly consequences on the material, end of life and the possible disassembly damage must be identified. These data guide the recycling process in order to minimize the variability incidence. In a second stage, the recycled material or reprocessed semi-product has to be tested in order to assess its quality and enrich the designer possibility (with a second life or reprocessed material). Figure 4 sums up the interaction between these three required skills. This picture gives an idea of the cyclonic cycle of the material properties moving from one field of application (high mechanical constrains) to other field (low mechanical constrains) (Perry et al., 2012). This downcycling view gives the possible use of the recycled material to the recycler and the designer. It allows developing final products (like sport devices with initial aeronautic material) or semi products (like patch). Mechanical models simulate the material behavior, including the size stochastic evolution of the recycle fibers, the random defects repartition (such as orientation, density) and the mix of initial material. These models help improving the recycling process, and optimize the design of the second life materials.

From the characterization point of view, the key problem is adaptation of scale. The testing pyramid strategy helps to identify sufficient and necessary tests from the elementary sample level to the full system level. In most cases, specific tests must be 
developed in order to guarantee relevant and reliable results. This multi level approach is also applied to the development of new recycling processes and their industrialization.

\section{Solvolysis and recycled fibers results}

\subsection{Recycled fibers level}

RECCO project (in which we are involved) search industrial solutions to recover (i.e. recycle and re-process) carbon composite wastes. The solvolysis method is developed to recycle thermoset matrix composites. The specificity of this process is its maximal matrix removal with a little carbon fibers degradation. After the solvolysis phase, dry carbon fibers remain, oriented according to the product composite sequence.

Solvolysis process heat the water at $400^{\circ} \mathrm{C}$ under a $200 \mathrm{bars}$ of pressure. The water is under super-critical conditions and become a very efficient solvent for any organic compound (even metallic). Using a flow in the High pressure vessel, the thermo-set matrix is removed in an average of 30 minutes (for around 10 centimeters of composites layers).The solvolysis has minimal water consumption and pollution. Nevertheless solvolysis vessel has size limitation. It implies cutting composite parts. Consequently, the cutting process impact the fiber reprocessing as illustrated in figure 5 .

Figure 5 EBM pictures of carbon fibers free (left) and glue at an edge due to cutting (right)
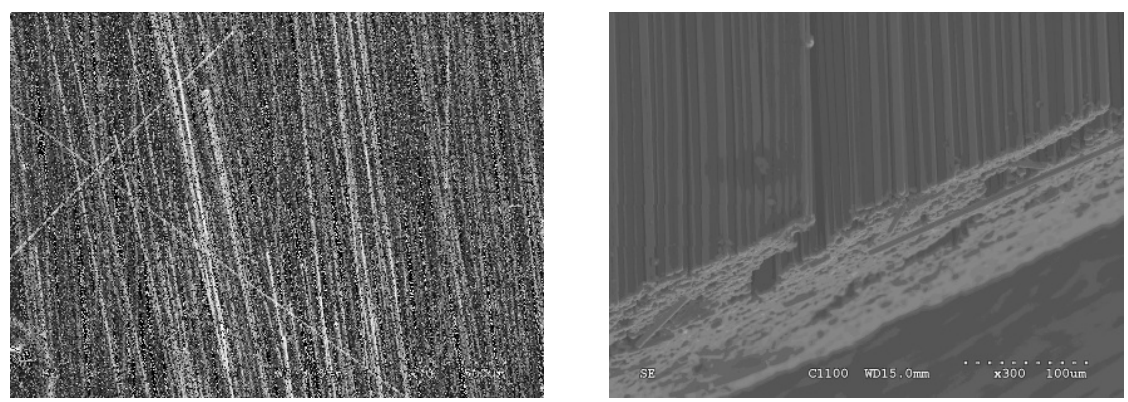

Nevertheless, this process is very sensitive to the presence of other non-organic material such as metal. For example, the solvolysis process oxidized rivets, screws or inserts, and even parts of the solvolysis reactor in some cases. It spreads small metallic particles in and on the carbon fibers as illustrated in figure 6. Depending on the whether uni-directional or woven orientation that was used for the fibers, the solvolysis liquid flow concentrates this pollution on the outer edge of the fibers or at the cross of the tows.

This pollution has little influence on the dry fibers mechanical strength. It creates bridges and an upper skin that reduces the re-process-ability (spinning or re-weaving). When sizing and imbue with matrix polymer it eases mechanical grip and has little effect on mechanical properties. Regarding the physical properties, this pollution modified the behavior locally. It results a metallic fraction limit in the global composite volume that have to be reduced and mastered before solvolysis. This point included a specific phase in the dismantling process in order remove all the metallic elements. It could be coupled with the cutting step in order to cut efficiently both composite parts and fixing elements. 
When the complete removal is not possible, a metallic fraction measurement is needed to ensure a limitation of the metallic pollution.

Figure 6 EBM pictures of clean and polluted recycled carbon fibers

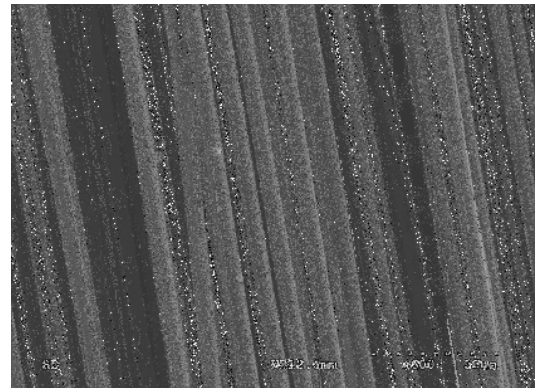

Recycled fiber with small silicates

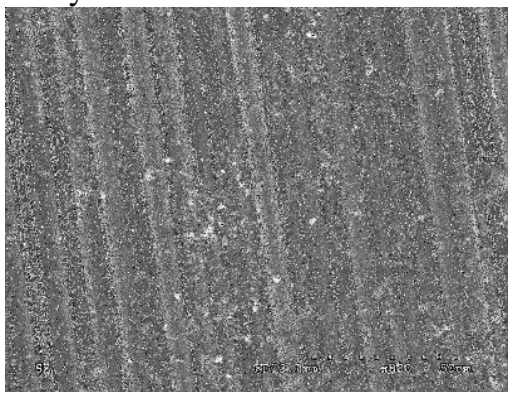

Recycled fibers with considerable and

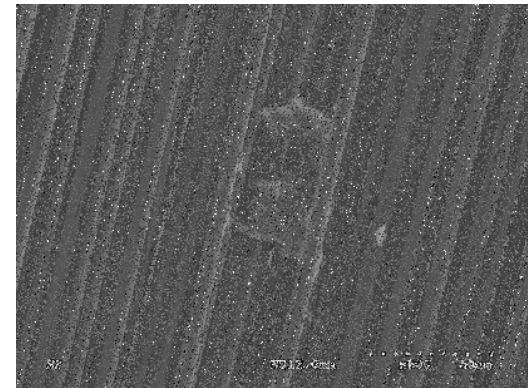

Fibers with slight nickel pollution

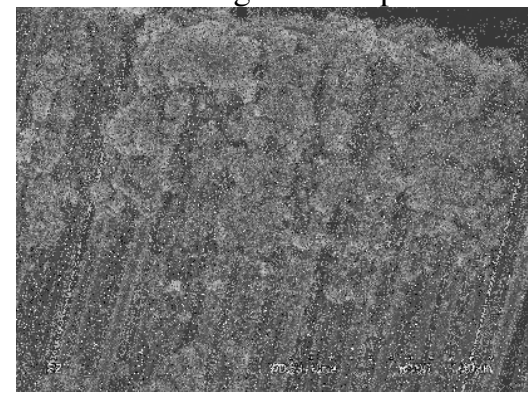

Fibers with edge pollution overall pollution from steel $(\mathrm{Fe}+\mathrm{Cr})$

Another feedback has resulted from the analysis of these pollutions. At the edge of the parts, the cutting processes change the properties of the matrix. This cutting comes from the adjustments of the parts to the solvolysis reactors sizes. Indeed, the local heat of the cutting burns the matrix. This carbon based layer (as illustrated in figure 5) glues the fibers together at their edges. This thickness of this layer can reach up to 200 microns when hard condition cutting parameters are used. This property can ease the handling of the recyclate. To spin a long tow with short or medium size fibers, this glue reduces the shreds (good for mechanical handle and for keeping fibers aligned. However, at the same time it reduces the spinning efficiency of inter fibers grip. We tested different cutting solutions such as water jet, machining and grinding in order to measure their edge's impact. These results give best practices for dismantling solution. All the process that locally does not heat the material fit with the best handling fibers' properties.

Up to now, we have integrated design competences in textile manufacturing in order to develop the remanufacturing end of the recovery loop. The pilot demonstrator is under development and we are able to transform composite parts to tows or woven of recycled carbon fibers. The mechanical characteristics of these fibers are nearly the same as virgin fibers, except for their length.

\subsection{Recycled product level}

Different applications are developed based on the recycled and re-aligned carbon fibers. The application domains are tight due to the early emergence of this material. It is mainly 
sportive application due to the need of mechanical properties expected. To proof the quality of the recycled carbon fiber, an application has been developed with a more general public target, and submitted to mechanical stresses to fit to a high-performance product. Natec manufactures one of the lightest racing bike pedal board in the world. A crank has been processed with recycled carbon fibers (see Figure 7).

Figure 7 Natec pedal crank : desired characteristics: stiffness and equivalent mass to the initial one (approx. $185 \mathrm{~g}$ )

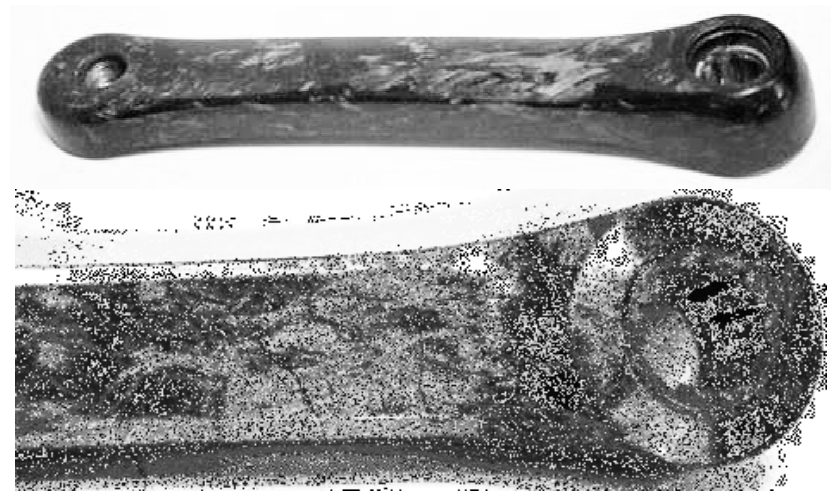

This product shows a very acceptable aspect. The zoom illustrates the today problematic of alignment of fibers that must be improved to propose nearly unidirectional semi product (if needed). This is a key point of the re-manufacturing process parameter. In this case, the non alignment of some fibers gives mechanical properties in the nearly $+/-30^{\circ}$ comparatively to the main $0^{\circ}$ orientation in the length of the crank. It gives the possibility to have only nearly $0^{\circ}$ layer instead of woven or $0 / 90^{\circ}$ layers. The final crank mass is $187 \mathrm{~g}$ versus $163 \mathrm{~g}$ for the initial mass-product with virgin fibers. The fiber placement and displacement has been observed during the process. No specific defects are identified. This validates the possibility of using second generation fibers by compression molding.

\section{Conclusions}

We were able to recycle carbon-based composites and recover the carbon fibers. This development highlights the fact that recycling possibilities and constraints should be included in the early design stages. Skills and competences (knowledge and know-how) from materials characterization and mechanical characterization are required in order to provide information about the parts to be recycled, and about the materials or semiproducts derived from recycling. From our point of view, the three communities have the skills that must interweave in order to reach the design under recycling constraint objectives and to develop robust recycling processes for second design perspectives. In order to facilitate discussion and communication within the three areas of expertise, we have to work on the definitions of the requirements for and from the designer, but we must also take the recycler's point of view into account. Systematic formalization of requirements and semantic alignment between the different (yet not so distant) communities has to be implemented. 
An environmental assessment of the solvolysis recycling process still has to be carried out in order to compare energy and material consumption, pollution, cost, etc. for the same quantity of material (new or recycled). The increasing use of composites in industry has brought about the development of end-of-life solutions. Regulatory constraints and financial perspectives (cost-cutting) will give rise to design for recovery or eco-design approaches.

\section{References}

Aymonier C., Loppinet-Serani A., Reverón H., Garrabos Y., Cansell F. (2006) Review of supercritical fluids in inorganic materials science, The Journal of Supercritical Fluids, Volume 38, Issue 2, September, pp. 242-251

Bernard A., Ammar-Khodja S., Perry N., Laroche F. (2007) Virtual Engineering based on knowledge integration, Virtual and Physical Prototyping, vol.2, issue 3, pp. 137-154

Berry S. (1996) Design for recycling, J. of Engineering Designer. Vol. 22, no. 4, pp. 8-14

Boothroyd G., Alting L. (1992) Design for Assembly and Disassembly, CIRP Annals Manufacturing Technology, Volume 41, Issue 2, pp. 625-636

Bourmaud A., Baley C. (2009) Rigidity analysis of polypropylen/vegetal fibre composites after recycling, Polymer degradation and stability Journ. 92(6), pp. 1034-1045

Braungart M., McDonough W., Bollinger A. (2007) Cradle-to-cradle design: creating healthy emissions - a strategy for eco-effective product and system design, Journal of Cleaner Production, Volume 15, Issues 13-14, pp. 1337-1348

Calcott P., Walls M. (2005) Waste, recycling and design for environment: Role of markets and policy instruments, Resource and energy Economics Journ. 27-4, pp.287-305

Cunliffe, A.M., Jones, N., Williams, P.T. (2003) Pyrolysis of composite plastic waste. Environ. Technol. 24-5, 653-663. 2003

Dennison A. (2010) The Test Pyramid: A Framework for consistent evaluation of RFID tags from design and manufacture to end use, www.idspackaging.com/Common/Paper/Paper_256/ The test pyramid.pdf (visited on the 12/09/2012)

Feng L.Y. (2010) The biomaterial for green composites, JEC Composites Journal ${ }^{\circ} 55$, focus on Natural Fibres \& Environment, pp.29-30

Ferro P., Amaral J. (2006) Design for recycling in the automobile industry: new approaches and new tools, Journal of Engineering Design, Volume 17, Issue 5 October 2006, pages 447-462

Gaustad G., Olivetti E., Kirchain R. (2010) Design for Recycling: Evaluation and Efficient Alloy Modification, Journal of Industrial Ecology, 14-2, pp.286-308

Hauschild, M.Z., Jeswiet, J., Alting, L. (2004) Design for Environment approaches? Do We Get the Focus Right? CIRP Annals - Manufacturing Technology, 53-1, p.1-4

Kriwet A., Zussman, E. Seliger G. (1995) Systematic integration of design-for-recycling into product design, International Journal of Production Economics, Volume 38, Issue 1, March 1995, Pages 15-22

Kromm F.X., Lorriot T., Coutand B., Harry R., Quenisset J.M. (2003) Tensile and creep properties of ultra high molecular weight PE fibres, Polymer Testing, Volume 22, Issue 4, June, Pages 463-470

Ladevèze P., Puel G., Romeuf T. (2006) Lack of knowledge in structural model validation, Computer methods in applied mechanics and engineering, 195-37, pp.4697-4710

Laurin F. (2005) Approche multiéchelle des mécanismes de ruine progressive des matériaux stratifiés et analyse de la tenue de structures composites, PHD Thesis, Univ de Franche-Comté, Fr 
Loppinet-Serani A., Aymonier C., Cansell F. (2010) Supercritical water for environmental technologies, Emerging Technologies, Journal of Chemical Technology \& Biotechnology, Volume 85 Issue 5, Pages 583 - 589, DOI 10.1002/jctb.2323

Mantaux O., Aymonier C., Antal M. (2009) Recycling of carbon fibre reinforced composite materials with super- critical water dissolution, 16th Journées Nationales Composites Proceeding, Toulouse, juin

Mantaux O., Chibalon L., Lorriot Th., Aurrekoetxea J., Puerto A., Arostegi A., Urrutibeascoa, I. (2004) Recycling study of end of life products made of ABS resin, Journal of Materials and Science \& Technology, Vol. 20, suppl-1, pp.125-128

McDonough W., Braungart M. (2002) Cradle to Cradle: Remaking the Way We Make Things, North Point Pr. pp. 56-57. ISBN 9780865475878

McDonough W., Braungart M., Anastas P.T., Zimmerman J.B. (2003) Peer Reviewed: Applying the Principles of Green Engineering to Cradle-to-Cradle Design, Environ. Sci. Technol., 2003, 37 (23), pp 434A-441A

Mohamad M. (2010) Natural fibres for the 3rd millenium, JEC Composites Journal ${ }^{\circ}{ }^{\circ 55}$, focus on Natural Fibres \& Environment, pp.23-28

Nonaka, I., Toyama, R., Konno N. (2000) SECI, Ba and Leadership: a Unified Model of Dynamic Knowledge Creation, California Management Review, Long range planning, 33(1), pp. 5-34.

Perry N., Bernard A., Laroche F., Pompidou S. (2012) Improving design for recycling - Application to composites, CIRP Annals - Vol.61/1, pp. 151-154

Perry N., Kromm F.X., Mantaux O., Pilato A. (2010) Composite eco-design, IFIP AMPS 2010 Conference, Como, Italia

Perry N., Mantaux O., Leray D., Lorriot T. (2010) Composite recycling: design for environment approach requirements, IDMME - Virtual Concept 2010, Bordeaux, France

Pimenta, S. et Pinho, S.T. (2011) Recycling carbon fibre reinforced polymers for structural applications: Technology review and market outlook, Waste Management 31 (2), pp. 378-392.

Piñero-Hernanz, R., Garcia-Serna, C. (2008) Chemical recycling of carbon fibre reinforced composites in nearcritical and supercritical water, Composites Part A: Applied Science and Manufacturing, Vol. 39 (3), pp. 454-461.

REACh (2006) Registration, Evaluation, Authorisation and Restriction of Chemicals (REACH), European Parliament and Council Regulation (EC) No 1907/2006

Rollet Y. (2007) Vers une maitrise des incertitudes en calculs des structures composites, PHD Thesis, ONERA - Ecole Polytechnique, Palaiseau, Fr

Rosemann B., H. Meerkamm, St. Trautner, K. Feldmann (1999), Design for recycling, recycling data management and optimal end-of-life planning based on recycling-graphs, ICED 99 Munich, August

Seager T.P., Theis T.L. (2004) A taxonomy of metrics for testing the industrial ecology hypotheses and application to design of freezer insulation, J. of Cleaner Production, 12-8, pp.865-875

Vallet F., Millet D., Eynard B. (2010) How ecodesign tools are really used - Requirements list for a context-related ecodesign tool, CIRP Design Conf. Proceeding, April, Nantes, France

Wallace, D.R., Suh N.P. (1993) Information-based design for environmental problem solving, CIRP Annals - Manufacturing Technology, Vol. 42/1, P.175,

Weager B. (2010) High-performance biocomposites: novel aligned natural fibre reinforcments, JEC Composites Journal ${ }^{\circ} 55$, Focus on Natural Fibres \& Environment, pp.31-35

WEEE (2002) Waste Electrical and Electronic Equipment (WEEE), Directive 2002/96/EC of the European Parliament and of the Council of 27 January 2003 